OPEN ACCESS

\title{
University of Dundee
}

Can angiotensin-converting enzyme inhibitors reduce the incidence, severity, and duration of radiation proctitis?

Alashkham, Abduelmenem; Paterson, Catherine; Rauchhaus, Petra; Nabi, Ghulam

Published in:

(IJROBP)

DOI:

10.1016/j.jijobp.2015.09.013

Publication date:

2016

Licence:

CC BY-NC-ND

Document Version

Peer reviewed version

Link to publication in Discovery Research Portal

Citation for published version (APA):

Alashkham, A., Paterson, C., Rauchhaus, P., \& Nabi, G. (2016). Can angiotensin-converting enzyme inhibitors reduce the incidence, severity, and duration of radiation proctitis? (IJROBP), 94(1), 93-101.

https://doi.org/10.1016/j.ijrobp.2015.09.013

\section{General rights}

Copyright and moral rights for the publications made accessible in Discovery Research Portal are retained by the authors and/or other copyright owners and it is a condition of accessing publications that users recognise and abide by the legal requirements associated with these rights.

- Users may download and print one copy of any publication from Discovery Research Portal for the purpose of private study or research.

- You may not further distribute the material or use it for any profit-making activity or commercial gain.

- You may freely distribute the URL identifying the publication in the public portal.

Take down policy

If you believe that this document breaches copyright please contact us providing details, and we will remove access to the work immediately and investigate your claim. 
Can the angiotensin converting enzyme inhibitors (ACEIs) reduce incidence, severity and duration of radiation proctitis?

${ }^{1}$ Abduelmenem Alashkham, MSc, ${ }^{1}$ Catherine Paterson, PhD, ${ }^{2}$ Petra Rauchhaus, BSc, ${ }^{1}$ Ghulam Nabi, FRCS

${ }^{1}$ Academic section of Urology, Division of Imaging and Technology, School of Medicine, University of Dundee, Scotland, UK

${ }^{2}$ Tayside Clinical Trials Unit (TCTU), School of Medicine, University of Dundee, Scotland, UK

Running title: ACEIs and radiation induced proctitis

DOI -10.1016/j.ijrobp.2015.09.013

\section{Corresponding author:}

Abduelmenem Alashkham MBBCH, MSc

Division of Imaging and Technology

Medical Research Institute,

School of Medicine

University of Dundee

Dundee

DD1 9SY

Tel: 00447853857313

E-mail: alashkham@yahoo.com

Acknowledgments: We gratefully acknowledge Professor Stephen Hubbard for his assistance and the funding of this work by Prostate Cancer, UK.

Conflict of interest: none. 


\begin{abstract}
:
Purpose: To determine whether participants on ACEIs treated with radical radiotherapy with neoadjuvant/adjuvant hormonal therapy have less incidence, severity and duration of radiation proctitis.
\end{abstract}

Methods and Materials: A propensity score analysis of $n=817$ patients who underwent radical radiotherapy with neoadjuvant/adjuvant hormonal therapy as primary line management in cohort study during 2009 to 2013 has been conducted. Patients were stratified into: (1) hypertensive on ACEIs (as a study group), (2) non-hypertensive not on ACEIs and (3) hypertensive not on ACEIs (both as a control group). The incidence, severity and duration of proctitis were the main outcome. Chi-square, Mann-Whitney U, ANOVA, risk ratio, confidence interval, Kaplan-Meier plots and Log-Rank tests were used.

\title{
Results:
}

The mean age of the participants was 68.91 years with a follow-up of 3.38 years. Based on disease and age matched comparison there was a statistically significant difference of proctitis grading between the three groups $\chi^{2}(8, n=308)=72.52, p<0.001$. The MannWhitney $U$ test indicated that grades of proctitis were significantly lower in hypertensive on ACEIs group than non-hypertensive not on ACEIs and hypertensive not on ACEIs groups $(p<0.001)$. The risk ratio of proctitis in hypertensive on ACEIs group was significantly lower than hypertensive not on ACEIs group (RR 0.40, 95\% CI, $0.30-0.53, \mathrm{p}<0.001$ ) and nonhypertensive not on ACEIs group (RR 0.58, 95\% CI, $0.44-0.77, \mathrm{p}<0.001$ ). Time to event analysis revealed that hypertensive on ACEIs group was significantly different comparing to the control groups $(\mathrm{p}<0.0001)$. Furthermore, hypertensive on ACEIs group has significantly faster resolution of proctitis $(\mathrm{P}<0.0001)$. 
Conclusion: Patients who were on ACEIs were significantly less likely to have high grade proctitis after radical radiotherapy with neoadjuvant/adjuvant hormonal therapy ( $\mathrm{p}<0.001)$. The intake of ACEIs were significantly associated with reduced risk of radiation induced proctitis as well as accelerating its resolution.

Keywords: Prostatic cancer; Radiotherapy; Proctitis; Angiotensin converting enzyme inhibitors, Pneumonitis; Nephritis.

\section{Introduction:}

Since the introduction of the prostate-specific antigen (PSA) testing in prostate cancer screening, more patients are now diagnosed earlier, and subsequently have undergone radical treatment (1). One option in clinical management of prostate cancer is radical radiotherapy $(2,3)$. However, proctitis is one of the complications of prostatic radiotherapy and can have a profound negative affect on patients' overall quality of life $(4-7)$. The initial step of proctitis is cell death and cell depletion leading to loss of the epithelium lining and as a consequence it causes oedema and mucosal inflammation which later leads to ulceration and sepsis. By the time it spreads to submucosa and provokes a regenerative response which in turn causes either normal tissue repair or ulceration, fibrosis and stricturing. Obliteration, fibrosis and angiogenesis lead to the clinical manifestations of rectal bleeding, tenesmus, diarrhoea and strictures $(8-11)$.

Experimental studies showed that the ACEIs may prevent development of radiation-induced injuries in certain tissues $(12-14)$. ACEIs are anti-hypertensive drugs that block the enzyme and prevent conversion of angiotensin I to angiotensin II which plays an important role in controlling the blood pressure. Previous studies have focused on the effect of ACEIs in prevention of radiation induced lung toxicity. Four animal studies $(12-16)$ conducted between 1988 and 2009, have all reported consistent results of the protective effect of the 
ACEIs in lung parenchyma yielded beneficial outcomes in terms of reducing the incidence of radiation-induced pneumonitis. In lung cancer patients, there have been four clinical studies (14, 17 - 19) conducted between 2000 and 2013. One study (14) reported a beneficial effect of ACEIs $(n=146)$ in preventing radiation induced lung injury using multivariate analysis. Other studies have not identified any significant association between ACEIs and radiation pneumonitis in individuals affected by lung cancer $(17-19)$.

Studies have also investigated the relationship between ACEIs and radiation-induced nephritis. To date, ten studies $(20$ - 29) have been conducted between 1986 and 2014. Most studies have reported consistent results in the beneficial association between ACEIs and reduced risk of renal toxicity, albeit the majority of these studies (90\%) were animal studies. Only (29) reported that all ACEIs mitigate radiation nephropathy except fosinopril. Elsewhere, (22) did not report any association between ACEIs and reduced risk of radiationinduced nephritis in a patient population of lung cancer patients.

Moreover, two animal studies $(30,31)$ have demonstrated that the intake of ACEIs have reduced the prevalence of radiation induced brain injuries, including cognitive impairment and optic neuropathy. Other studies have explored the association between ACEIs and gastrointestinal (GI) toxicity. Six clinical studies $(32-37)$ have been conducted between 2004 and 2012, and all investigated the effect of hypertension on normal tissue radiation induced toxicity. Three of which $(32,34,37)$ have consistently reported a beneficial effect of the ACEIs on GI tract toxicity. In one animal study, (26) did not find any association between the ACEIs and GI tract toxicity.

To date, there have been a number of studies (animal and human) investigating the potential association between ACEIs and its protective effects on reducing the incidence of radiationinduced injuries in renal, brain, GI tract and pelvic cancer. To the best of our knowledge, no 
study has explored the effect of ACEIs and in men affected by prostate cancer treated by radical radiotherapy with neoadjuvant/adjuvant hormonal therapy. We aimed to evaluate whether the concurrent use of ACEIs decrease the incidence, severity and duration of radiation induced proctitis in prostatic cancer patients treated by radical radiotherapy.

\section{Methods and Materials:}

The study had Caldecott Institutional Approval (Caldicott/CSAppGN021211). During January 2007 and December 2013, all consecutive patients who underwent radical radiotherapy and neoadjuvant/adjuvant hormonal therapy were identified from comprehensive clinical databases hosted at one of main cancer centres in the UK. Patients were identified from electronic databases through a validated cross linkage methodology as described previously by our group $(38,39)$. Record linkage technique brings together two or more records relating to the same individual identified by a common identifier (Community Health Index $[\mathrm{CHI}]$ number in this series). Cross-linkage of databases enabled demographical and clinical data to be securely managed at one centralised database for the purpose of this study.

The database with (CHI) was linked to the following clinical systems:

(i) WISDOM oncology system (Web Information System for Data Oncology Management) which securely stores the following clinical information: clinical presentation, PSA, cancer stage, Gleason score, radiotherapy, chemotherapy, clinical complications, follow-up and mortality

(ii) Referral Management System (RMS) which is a primary care system for a population of more than 400,000 individuals. Data linkage captured the doses, start date of ACEIs and name of medication $(38,39)$. 
(iii) Multidisciplinary Board Meeting (MDT) records where all men diagnosed with prostate cancer are discussed on a weekly basis.

(iv) Integrated Clinical Environment (ICE) system provides clinicians with diagnostic services as a means to electronically order tests and view results. Using the $\mathrm{CHI}$ number we searched for sequential PSA results.

(v) Records were searched using Clinical Portal and the In House Surgical Information System web and Technology (Insite), these databases host secure electronic patient records which systematically captures follow-up history including communication between acute and primary care.

Inclusion criteria were: (I) patients who are newly diagnosed and histologically confirmed localized or locally advanced adenocarcinoma of prostate; (II) patients who acquired primary radical radiotherapy and neoadjuvant/adjuvant hormonal therapy; (III) patients who received a dose of radiotherapy ranged between $4500 \mathrm{cGY}-5700 \mathrm{cGY}$ in 20 fraction over 20 to 32 days; (IV) patients acquired 3D field conformal radiotherapy; (V) patients prescribed ACEIs before (at least 6 months) and during the course of prostate radiotherapy; and (VI) patients who were on ACEIs combined with other anti-hypertensive medications before (at least 6 months) and during the course of prostate radiotherapy. Exclusion criteria were: (1) patients who received adjuvant radiotherapy following radical prostatectomy; (2) patients with missing data including lack of the dose of radiotherapy, tumour stage, Gleason score, PSA or no history of follow-up; (3) patients who have radiotherapy only; and (4) haemorrhoids.

The incidence, severity and duration of all types of radiation induced proctitis were the primary study outcome. Radiation induced proctitis was graded according the European Organization for Research and Treatment of Cancer (EORTC) and the Radiation Therapy Oncology Group (RTOG) grading system of radiation proctitis $(40,41)$ (supplementary Table 
1). The records were assessed for grading classification by two members of the research team (AA and $\mathrm{CP}$ ) to rate the severity of proctitis for each patient within the study. Inter-rater reliability between the observers was assessed using the Kappa statistic (Kappa=0.809 with $\mathrm{p}<0.001)$ and was found to have substantial agreement (42).

Patients were stratified according to the ACEIs usage into: group (1) hypertensive on ACEIs (as a study group), group (2) non-hypertensive not on ACEIs and group (3) hypertensive not on ACEIs (both as a control group). The two control groups (non-hypertensive not on ACEIs and hypertensive not on ACEIs) were identified from the same centralised database. The hypertensive not on ACEIs group consisted of hypertensive patients that were treated by other types of antihypertensive medications including calcium channel, beta or alpha blockers.

In statistical analysis of observation data, propensity score-matching method is an alternative statistical technique to randomization which estimates the effect of treatment and reduces the bias of confounding variables $(43,44)$. The propensity score-matched method was used to balance any observed covariates between the groups. It was created using disease specific and non-disease specific variables including: age, tumour stage, Gleason score, PSA level before and co-morbidities. Participants acquiring radiotherapy and neoadjuvant/adjuvant hormonal therapy were matched on a one-to-one case base. Matching was accomplished based on the closest-neighbour matching $(43,44)$.

The three groups were treated in the same cancer centre with neoadjuvant and adjuvant hormone therapy and radiotherapy. Each group in the study were treated by three field conformal radiotherapy with a median dose of 5400cGY (ranged, 4500cGY - 5700cGY), 20 fraction (ranged, 19 - 22) and 28 days (ranged, 20 - 32) following UK guidelines (45). 
To compare the contrast in proportions of baseline characteristics between the study and the two control groups, $\chi^{2}$ was used. The ANOVA, risk ratio (RR) and confidence interval (CL) tests were performed using SPSS.21. In follow-up Mann-Whitney U test was used. Using Bonferroni adjusted alpha level less than 0.017 was considered to be significant. Time from radiotherapy to onset of proctitis was compared between study and control groups using Kaplan-Meier plots and Log-Rank test. Furthermore, time from radiotherapy to resolution of proctitis was also compared between study and control groups using Kaplan-Meier plots and Log-Rank test.

\section{Results:}

The clinical and demographic characteristics of the study participants are presented in Table (2). The total number of patients who underwent 3D radical radiotherapy with neoadjuvant/adjuvant hormonal treatment as primary line management in the cohort study was 817 . Of 817 there were 389 patients with hypertension and 428 non-hypertensive patients. Based on the inclusion and exclusion criteria and the propensity score matched analysis, $\mathrm{n}=308$ participants were included in this study.

The overall mean age of the participants in the study was 68.91 (SD, 5.67) years with a follow-up of 3.38 (SD, 1.95) years. Of 308 there were $n=102$ participants in hypertensive on ACEIs group with a mean age 68.64 (SD, 5.31) years and follow-up of 3.27 (SD 1.90) years, 103 participants in hypertensive not on ACEIs group with a mean age 68.61 (SD, 5.59) years and follow-up of 3.73 (SD 2.10) years and 103 participants in non-hypertensive not ACEIs group with a mean age of $68.49(\mathrm{SD}, 6.11)$ years and follow-up of $3.15(\mathrm{SD}, 1.82)$ years.

The distribution of clinical characteristics in all participants were found as: T1 was found in $\mathrm{n}=22(7.1 \%)$, Gleason score $2-6, \mathrm{n}=11(50 \%)$, Gleason score $7, \mathrm{n}=8(36.4 \%)$ and Gleason score $8-10 \mathrm{n}=3$ (13.6\%); T2 in $\mathrm{n}=124(40.3 \%)$, Gleason score $2-6 \mathrm{n}=22(17.7 \%)$, Gleason 
score 7: $\mathrm{n}=39(31.5 \%)$ and Gleason score $8-10 \mathrm{n}=63(50.8 \%)$; and T3 $\mathrm{n}=162(52.6 \%)$, Gleason score $2-6 \mathrm{n}=8(4.9 \%)$, Gleason score $7(3+4) \mathrm{n}=38(23.5 \%)$ and Gleason score 7 $(4+3)-10 \mathrm{n}=116(63.7 \%)$. Based on disease and age matched comparison there was a statistically significant difference of proctitis grading between the three groups $\chi^{2}(8, n=308)$ $=72.52, \mathrm{p}<0.001$. The Mann-Whitney $\mathrm{U}$ test indicated that grades of proctitis were significantly lower in hypertensive on ACEIs group $(\mathrm{Md}=83.08, \mathrm{n}=102)$ than nonhypertensive not on ACEIs group $(\mathrm{Md}=122.72, \mathrm{n}=103), \mathrm{U}=3221.5, \mathrm{z}=-5.243, \mathrm{p}<0.001$, $\mathrm{r}=0.36$, or hypertensive not on ACEIs group $(\mathrm{Md}=132.25, \mathrm{n}=103), \mathrm{U}=2240.5, \mathrm{z}=-$ 7.631, $\mathrm{p}<0.001, \mathrm{r}=0.53$. The Mann-Whitney $\mathrm{U}$ test also indicated that grades of proctitis were higher in hypertensive not on ACEIs group ( $\mathrm{Md}=108.74, \mathrm{n}=103)$ than that of nonhypertensive not on ACEIs group ( $\mathrm{Md}=98.26, \mathrm{n}=103), \mathrm{U}=4765, \mathrm{z}=1.32, \mathrm{r}=0.09$, but the difference was not significant.

Table 3 shows that in the hypertensive on ACEIs group, the incidence of grades 0 and 1 proctitis constituted $96.1 \%(\mathrm{n}=98)$ whereas grades 2 and 3 proctitis were observed in $2.9 \%$ $(n=3)$ and $1 \%(n=1)$ : no grading of 4 or 5 proctitis was observed. By contrast, in the nonhypertensive group grades 0 and 1 were observed only in $60.2 \%(n=62)$; however, grades 2,3 and 4 proctitis were found in $31.1 \%(n=32), 6.8 \%(n=7), 1.9 \% \quad(n=2)$ respectively. In hypertensive and not on ACEIs group, grades 0 and 1 proctitis constituted $66 \%(\mathrm{n}=68)$ whereas grades 2, 3 and 4 proctitis were seen in $24.3 \%(n=25), 7.8 \%(n=8)$ and $1.9 \%(n=2)$ respectively (Figure 1).

The risk ratio of proctitis in hypertensive on ACEIs group was significantly lower than both hypertensive not on ACEIs group (RR 0.40, 95\% CI, $0.30-0.53, \mathrm{p}<0.001$ ) and nonhypertensive not on ACEIs group (RR 0.58, 95\% CI, $0.44-0.77, \mathrm{p}<0.001)$. Furthermore, risk ratio of proctitis in non-hypertensive not ACEIs group was significantly lower than hypertensive not on ACEIs (RR 0.74, 95\% CI. 1.34 - 3.56, p<0.001). 
The onset of proctitis in hypertensive on ACEIs group was significantly different comparing to the two control groups $(\mathrm{P}<0.0001)$ (Figure 2). In regards to time to resolution of proctitis, It was observed that hypertensive on ACEIs group has significantly experienced shorter time of proctitis comparing to non-hypertensive not on ACEIs and hypertensive not on ACEIs groups $(\mathrm{P}<0,0001)$ (Figure 3).

There was no significant differences were found between grades of proctitis and PSA level before treatment, follow-up, tumour stages or Gleason scores among the three groups.

\section{Discussion}

To our knowledge this is the first study to investigate the relationship between the use of ACEIs and the incidence, severity and duration of radiation induced proctitis. Based on the propensity score matched analysis and the EORTC and RTOG grading classification our findings suggest that the use of ACEIs during prostate radical radiotherapy is significantly associated with a low grade proctitis. Our findings are in keeping with other studies that have identified the beneficial effects of concurrent use of ACEIs on reducing radiation induced injuries including radiation induced pneumonitis (12), nephritis (29), GI tract toxicity (37) and brain injury (30). A key advantage of our study was that propensity score matched analysis and the EORTC and RTOG grading classification of toxicity was used. These two elements enhance the investigation of clinical signs and decrease the risk of bias in this study.

Several studies have reported consistent results in the beneficial association between ACEIs and reduced risk of renal toxicity $(20-29)$. Our findings observed that the intake of the ACEIs was significantly associated with reduced risk of radiation induced proctitis. Elsewhere, (22) did not report any association between ACEIs and reduced risk of radiationinduced nephritis in a patient population of lung cancer patients. 
Our findings demonstrated that the time of onset of proctitis in hypertensive on ACEIs group was significantly different when compared to the two control groups $(\mathrm{p}<0.0001)$ : with the majority of proctitis in ACEIs group took place in the first few weeks after radical radiotherapy. Furthermore, it was observed that hypertensive on ACEIs group had significantly faster resolution of proctitis $(\mathrm{P}<0.0001)$, with little difference between the two control groups. These findings suggest that ACEIs help to reduce the incidence of proctitis after radical radiotherapy as well as accelerating the resolution of proctitis. While the mechanism of action of ACEIs in reducing severity, incidence and resolution time of radiation induced proctitis are still unknown. Further studies are needed to inform the clinical recommendation of ACEIs administration in patients who are opting to have radical radiotherapy for prostate cancer, before and during treatment.

One of the major limitations of the existing evidence-base is the reliability and validity of the measurement of proctitis $(46,47,4-7)$. Specially, a range of studies have reported proctitis present or not present, and lacked the severity grading of proctitis $(5-7)$, this is a major limitation to the existing data in this area. We implemented reliable and validated methodology, the European Organization for Research and Treatment of Cancer (EORTC) and the Radiation Therapy Oncology Group (RTOG) grading system of radiation proctitis $(40,41)$. The prevalence data of the rectal toxicity was derived from our comprehensive clinical databases. The level of inter-rater reliability between the observers using this classification system was found to have a substantial agreement with Kappa $=0.809$ with $\mathrm{p}<0.001$. Our approach to grading the severity of proctitis has been verified by several studies $(48-50,36)$ and was found to be reliable and consistent.

Rectal bleeding is one of the signs of radiation induced proctitis $(51,52,4)$ which occurs due to mucosal friability and neovascular telangiectasias (53) with an average incidence up to $75 \%(46,47,4-7)$. In the current study there were few patients $(n=20)$ who had a history of 
haemorrhoids and were excluded from the analysis as the bleeding may have been secondary to the haemorrhoids and not proctitis.

This study stratified into three groups by cancer stage, Gleason score, PSA, age, medication data and comorbidities. Based on EORTC and RTOG grading system the CHI square test demonstrated that low severity proctitis was statistically associated with the use of the ACEIs $(\mathrm{P}<0.001)$ after controlling age, stage, Gleason score and comorbidity. The current study observed that the Mann-Whitney U test indicated the severe grades of proctitis were higher in hypertensive patients not on ACEIs group than non-hypertensive patients group. Furthermore, the risk of proctitis was also significantly higher in hypertensive patients not on ACEIs group than non-hypertensive patients group. These findings suggest that nonhypertensive patients experience lower grades of proctitis and were at lower risk of development of proctitis in comparison to those who were hypertensive not on ACEIs. Elsewhere, it has been suggested that hypertension reduces the risk of proctitis $(32,34,36)$. This area is in its infancy and further research is needed to clarify the moderating and mediating pathways of hypertension and the risk of proctitis in this patient population.

The use of multiple control groups is considered to be helpful in detection and balancing any hidden biases from any unobserved covariates and the estimation of the treatment effects become efficient (54). This study has used two control groups; the first was non-hypertensive not on ACEIs and the second was hypertensive not on ACEIs which was a strength to our study.

To date, there is no clear evidence that demonstrates an association between proctitis and PSA, Gleason score or staging: this is in keeping with our findings.

ACEIs are widely prescribed as a treatment for hypertension. ACEIs have reported to decrease radiation-induced injuries in renal, brain, GI tract $(29,30,37)$ in different models, 
although the underlying main, moderating and mediating mechanisms are yet to be unexplored. Various proposed mechanisms include the pharmacological component; that all type I angiotensin receptor blockers, L-158,809 and ACEIs containing sulphydryl radical were more effective in protection the lung against lung fibrosis (13). These findings bring into clinical question that if the beneficial effect was due to the inhibition of the enzyme or the associated drugs such as antioxidant. Due to the limited number of participants who were on ACEIs ( $n=102)$, this study was not sufficiently powered to identify which type of the ACEIs was associated with low grades proctitis. Given the important clinical implications of our findings further investigations in larger sample are suggested.

\section{Conclusion}

In summary, this is the first study to examine the association of ACEIs on radiation induced rectal toxicity in men diagnosed with prostate cancer. Our findings confirm that patients who were on ACEIs were significantly less likely to have high grade proctitis after radical radiotherapy with neoadjuvant/adjuvant hormonal therapy. Besides, the intake of ACEIs were significantly associated with reduced risk of radiation induced proctitis as well as accelerating its resolution. ACEIs may offer several advantages in pelvic radiotherapy treatment but the moderation and mediating pathways are yet to be explored. Further clinical research is needed which in turn could decrease morbidity and increase the quality of life after radiotherapy.

\section{References}

1. Shao YH, Albertsen PC, Shih W, et al. The Impact of Psa Testing Frequency on Prostate Cancer Incidence and Treatment in Older Men. Prostate Cancer and Prostatic Diseases 2011;14 (4): 332-39.

2. Shao YH, Albertsen PC, Roberts CB et al. Risk Profiles and Treatment Patterns 
among Men Diagnosed as Having Prostate Cancer and a Prostate-Specific Antigen Level Below 4.0 Ng/Ml. Archives of Internal Medicine 2010;170(14): 1256-61.

3. Kawachi MH, Bahnson RR, Barry M, et al. Prostate Cancer Early Detection. Clinical Practice Guidelines in Oncology. J Natl Compr Canc Netw 2007;5(7): 714-36.

4. Hayne D, Vaizey CJ, Boulos PB. Anorectal Injury Following Pelvic Radiotherapy. British Journal of Surgery 2001;88(8): 1037-48.

5. Goldner GM, Geinitz H, Wachter S, et al. Proctitis after 3d-Conformal Radiotherapy of Localized Prostate Cancer: Classification According to the Vienna Rectoscopy Score and Correlation to the Eortc/Rtog Score within the Austrian-German Multicenter Prostate Cancer Trial. International Journal of Radiation Oncology Biology Physics 2005;63(3): S314-S15.

6. Muren LP, Karlsdottir A, Kvinnsland Y, et al. Testing the New Icru 62 'Planning Organ at Risk Volume' Concept for the Rectum. Radiotherapy and Oncology 2005;75(3): 293-302.

7. Wachter S, Gerstner N, Goldner G, et al. Rectal Sequelae after Conformal Radiotherapy of Prostate Cancer: Dose-Volume Histograms as Predictive Factors. Radiotherapy and Oncology 2001;59(1): 65-70.

8. Denton AS, Clarke NW, Maher EJ. Non-Surgical Interventions for Late Radiation Cystitis in Patients Who Have Received Radical Radiotherapy to the Pelvis. Cochrane Database Syst Rev, 2002;3:CD001773.

9. Leiper K, Morris AI. Treatment of Radiation Proctitis. Clin Oncol (R Coll Radiol) 2007;19(9): 724-9.

10. Babb RR. Radiation Proctitis: A Review. Am J Gastroenterol 1996;91(7): 1309-11.

11. Varma JS, Smith AN, Busuttil A. Function of the Anal Sphincters after Chronic Radiation Injury. Gut 1986;27(5): 528-33. 
12. Ghosh SN, Zhang R, Fish BL, et al. Renin-Angiotensin System Suppression Mitigates Experimental Radiation Pneumonitis. Int J Radiat Oncol Biol Phys 2009;75(5): 1528-36.

13. Molteni A, Moulder JE, Cohen EF, et al. Control of Radiation-Induced Pneumopathy and Lung Fibrosis by Angiotensin-Converting Enzyme Inhibitors and an Angiotensin Ii Type 1 Receptor Blocker. Int J Radiat Biol 2000;76(4): 523-32.

14. Jenkins P, Welsh A. Computed Tomography Appearance of Early Radiation Injury to the Lung: Correlation with Clinical and Dosimetric Factors. Int J Radiat Oncol Biol Phys 2011;81(1): 97-103.

15. Ward WF, Molteni A, Ts'ao CH, et al. Captopril Reduces Collagen and Mast Cell Accumulation in Irradiated Rat Lung. Int J Radiat Oncol Biol Phys 1990;19(6): $1405-9$.

16. Ward WF, Kim YT, Molteni A, et al. Radiation-Induced Pulmonary Endothelial Dysfunction in Rats: Modification by an Inhibitor of Angiotensin Converting Enzyme. Int J Radiat Oncol Biol Phys 1988;15(1): 135-40.

17. Wang HM, Liao ZX, Zhuang Y, et al. Do Angiotensin-Converting Enzyme Inhibitors Reduce the Risk of Symptomatic Radiation Pneumonitis in Patients with Non-Small Cell Lung Cancer after Definitive Radiation Therapy? Analysis of a SingleInstitution Database. International Journal of Radiation Oncology Biology Physics 2013;87(5): 1071-77

18. Wang LW, Fu XL, Clough R, et al. Can Angiotensin-Converting Enzyme Inhibitors Protect against Symptomatic Radiation Pneumonitis?. Radiation Research 2000;153(4): 405-10.

19. Kharofa J, Cohen EP, Tomic R, et al. Decreased Risk of Radiation Pneumonitis with Incidental Concurrent Use of Angiotensin-Converting Enzyme Inhibitors and 
Thoracic Radiation Therapy." Int J Radiat Oncol Biol Phys 2012;84(1): 238-43.

20. Cohen EP, Robbins ME. Radiation Nephropathy. Semin Nephrol 2003;23(5): 486-99.

21. Cohen EP, Fish BL, Moulder JE. Treatment of Radiation Nephropathy with Captopril. Radiat Res 1992;132(3): 346-50.

22. Cohen, EP, Fish BL, Moulder JE. Mitigation of Radiation Injuries Via Suppression of the Renin-Angiotensin System: Emphasis on Radiation Nephropathy. Current Drug Targets 2010;11(11): 1423-29.

23. Geraci JP, Sun MC, Mariano MS. Amelioration of Radiation Nephropathy in Rats by Postirradiation Treatment with Dexamethasone and/or Captopril. Radiat Res 1995;143(1): 58-68.

24. Moulder JE, Cohen EP, Fish BL, et al. Prophylaxis of Bone Marrow Transplant Nephropathy with Captopril, an Inhibitor of Angiotensin-Converting Enzyme. Radiat Res 1993;136(3): 404-7.

25. Moulder JE, Fish BL, Cohen EP. Treatment of Radiation Nephropathy with Ace Inhibitors. Int J Radiat Oncol Biol Phys 1993;27(1): 93-9.

26. Moulder JE, Fish BL, Cohen EP. Noncontinuous Use of Angiotensin Converting Enzyme Inhibitors in the Treatment of Experimental Bone Marrow Transplant Nephropathy. Bone Marrow Transplant 1997;19(7): 729-35.

27. Robbins ME, Hopewell JW. Physiological Factors Effecting Renal Radiation Tolerance: A Guide to the Treatment of Late Effects. Br J Cancer Suppl 1986; 7: 2657.

28. Yildiz F, Atahan II, Yildiz O. Radiation Nephropathy in Rats and Its Modification by the Angiotensin Converting Enzyme Inhibitor Enalapril. Radiat Med 2000;18(3): $153-9$.

29. Moulder JE, Cohen EP, Fish BL. Mitigation of Experimental Radiation Nephropathy 
by Renin-Equivalent Doses of Angiotensin Converting Enzyme Inhibitors. International Journal of Radiation Biology 2014;90(9): 762-68.

30. Kim JH, Brown SL, Kolozsvary A, et al. Modification of Radiation Injury by Ramipril, Inhibitor of Angiotensin-Converting Enzyme, on Optic Neuropathy in the Rat. Radiation Research 2004;161(2): 137-42.

31. Brown WR, Thore CR, Moody DM, et al. Vascular Damage after Fractionated Whole-Brain Irradiation in Rats. Radiat Res 2005;164(5): 662-8.

32. Barnett, GC, De Meerleer G, Gulliford SL, et al. The Impact of Clinical Factors on the Development of Late Radiation Toxicity: Results from the Medical Research Council Rt01 Trial (Isrctn47772397). Clin Oncol (R Coll Radiol) 2011;23(9): 61324.

33. Cozzarini C, Fiorino C, Da Pozzo LF, et al. Clinical Factors Predicting Late Severe Urinary Toxicity after Postoperative Radiotherapy for Prostate Carcinoma: A SingleInstitute Analysis of 742 Patients. Int J Radiat Oncol Biol Phys 2012;82(1): 191-9.

34. Liu M, Pickles T, Agranovich A, et al. Impact of Neoadjuvant Androgen Ablation and Other Factors on Late Toxicity after External Beam Prostate Radiotherapy. Int $J$ Radiat Oncol Biol Phys 2004;58(1): 59-67.

35. Tucker SL, Dong L, Bosch WR, et al. Late Rectal Toxicity on Rtog 94-06: Analysis Using a Mixture Lyman Model. International Journal of Radiation Oncology Biology Physics 2010;78(4): 1253-60.

36. Vavassori V, Fiorino C, Rancati T, et al. Predictors for Rectal and Intestinal Acute Toxicities During Prostate Cancer High-Dose 3d-Crt: Results of a Prospective Multicenter Study. International Journal of Radiation Oncology Biology Physics 2007;67(5): 1401-10.

37. Wedlake LJ, Silia F, Benton B, et al. Evaluating the Efficacy of Statins and Ace- 
Inhibitors in Reducing Gastrointestinal Toxicity in Patients Receiving Radiotherapy for Pelvic Malignancies. Eur J Cancer 2012;48(14): 2117-24.

38. Ganeswaran D, Sweeney C, Yousif F, et al. Population-Based Linkage of Health Records to Detect Urological Complications and Hospitalisation Following Transrectal Ultrasound-Guided Biopsies in Men Suspected of Prostate Cancer. World J Urol 2014;32(2): 309-15.

39. El-Mokadem I, Budak M, Pillai S, et al. Progression, Interobserver Agreement, and Malignancy Rate in Complex Renal Cysts ( >/= Bosniak Category Iif). Urol Oncol 2014;32(1): 24 e21-7.

40. Pilepich MV, Krall JM, Sause WT, et al. Correlation of Radiotherapeutic Parameters and Treatment Related Morbidity in Carcinoma of the Prostate--Analysis of Rtog Study 75-06. Int J Radiat Oncol Biol Phys 1987;13(3): 351-7.

41. Zelefsky MJ, Fuks Z, Hunt M, et al. High-Dose Intensity Modulated Radiation Therapy for Prostate Cancer: Early Toxicity and Biochemical Outcome in 772 Patients. Int J Radiat Oncol Biol Phys 2002;53(5): 1111-6.

42. Viera, AJ, Garrett JM. Understanding Interobserver Agreement: The Kappa Statistic. Family Medicine 2005;37(5): 360-63.

43. D'Agostino RB. Propensity Score Methods for Bias Reduction in the Comparison of a Treatment to a Non-Randomized Control Group. Statistics in Medicine 1998;17(19): 2265-81.

44. Shao YH, Kim S, Moore DF, et al. Cancer-Specific Survival after Metastasis Following Primary Radical Prostatectomy Compared with Radiation Therapy in Prostate Cancer Patients: Results of a Population-Based, Propensity Score-Matched Analysis. Eur Urol 2014;65(4): 693-700.

45. Radiotherapy Dose-Fractionation. The Royal College of Radiologists. London; 2006. 
pp.1-156.

46. Placer C, Lizarazu A, Borda N, et al. Radiation Proctitis and Chronic and Refractory Bleeding. Experience with 4\% Formaldehyde. Cir Esp 2013;91(2): 111-4.

47. Mishra MV, Shirazi R, Barrett WL. Incidence and Clinical Course of Hemorrhagic Radiation Proctitis after Iodine-125 Prostate Brachytherapy. Clin Genitourin Cancer 2007;5(6): 397-400.

48. Muanza TM, Albert PS, Smith S, et al., Comparing Measures of Acute Bowel Toxicity in Patients with Prostate Cancer Treated with External Beam Radiation Therapy. International Journal of Radiation Oncology Biology Physics 2005;62(5): $1316-21$.

49. Talcott JA, Manola J, Clark JA, et al. Time Course and Predictors of Symptoms after Primary Prostate Cancer Therapy. J Clin Oncol 2003;21(21): 3979-86.

50. Goldner G, Wachter-Gerstner N, Wachter S, et al. Acute Side Effects During 3-DPlanned Conformal Radiotherapy of Prostate Cancer. Differences between Patient's Self-Reported Questionnaire and the Corresponding Doctor's Report. Strahlenther Onkol 2003;179(5): 320-7.

51. Sharma B, Pandy D, Chauhan V, et al. Radiation proctitis. JIACM 2005;6(2): 14651.

52. Counter SF, Froese DP, Hart MJ. Prospective Evaluation of Formalin Therapy for Radiation Proctitis. American Journal of Surgery 1999;177(5): 396-98.

53. Taylor JG, Disario JA, Buchi KN. Argon-Laser Therapy for Hemorrhagic Radiation Proctitis - Long-Term Results. Gastrointestinal Endoscopy 1993;39(5): 641-44.

54. Stuart EA, Rubin DB. Matching with multiple control groups and adjusting for group differences. Journal of Educational and Behavioral Statistics 2008; 33(3):279-306. 
Figure (1): Bar chart shows the distribution of the proctitis grading among hypertensive patients on ACEIs, non-hypertensive patients not on ACEIs and hypertensive not on ACEIs groups.

Figure (2): Kaplan Meier curves show time to event between hypertensive patients on ACEIs, non-hypertensive patients not on ACEIs and hypertensive not on ACEIs groups over a median 6 years of follow-up.

Figure (3): Cumulative incidence curve show time to resolution between hypertensive patients on ACEIs, non-hypertensive patients not on ACEIs and hypertensive not on ACEIs groups over a median 6 years of follow-up. 


\section{Incidence of proctitis grade across treatment groups}

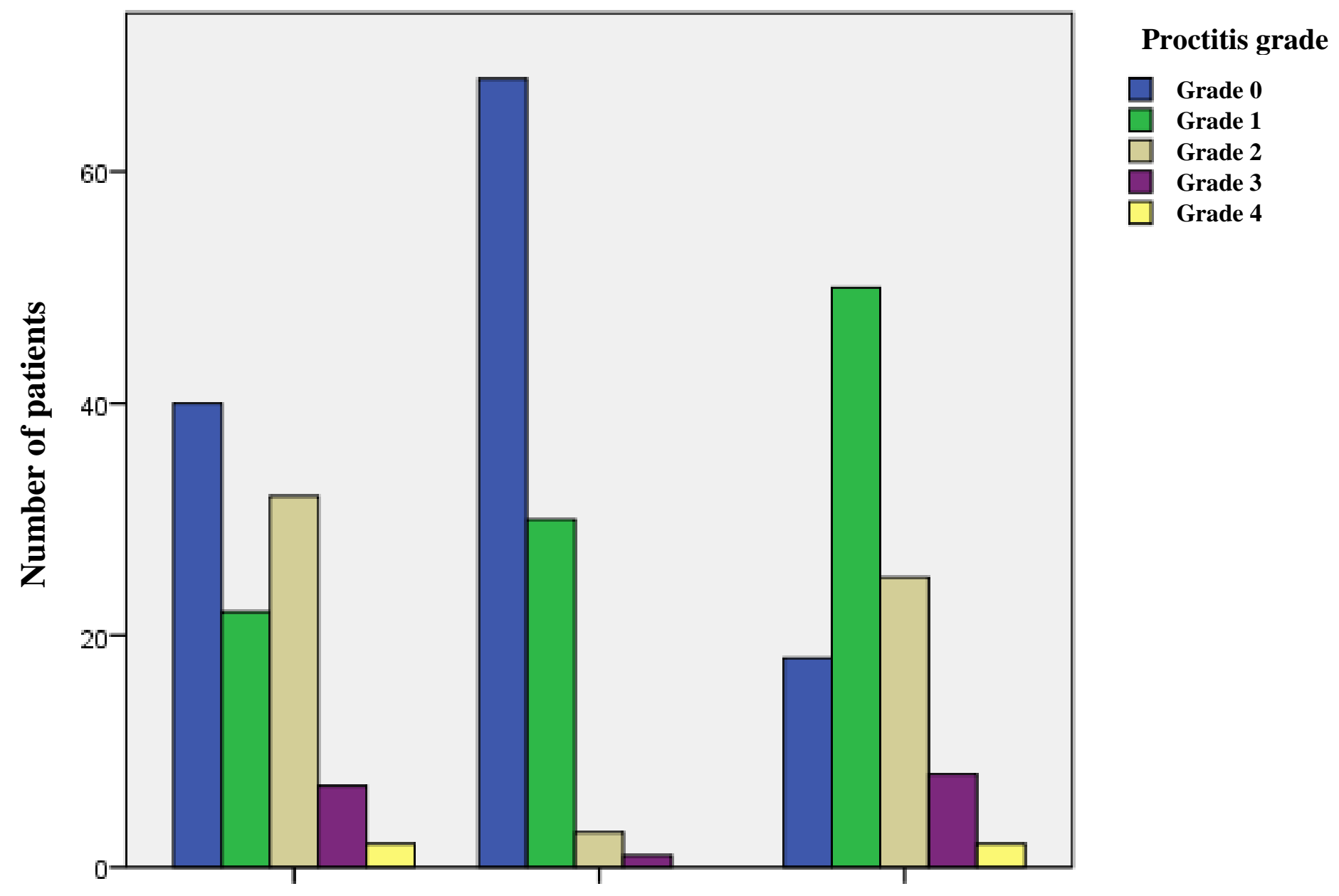

Non-hypertensive not on ACEIs Hypertensive on ACEIs Hypertensive not on ACEIs

\section{Treatment groups}

Figure (1): Bar chart shows the distribution of the proctitis grading among hypertensive patients on ACEIs, nonhypertensive patients not on ACEIs and hypertensive not on ACEIs groups. 


\section{Time to onset of proctitis}

With Number of Subjects at Risk and 95\% Confidence Limits

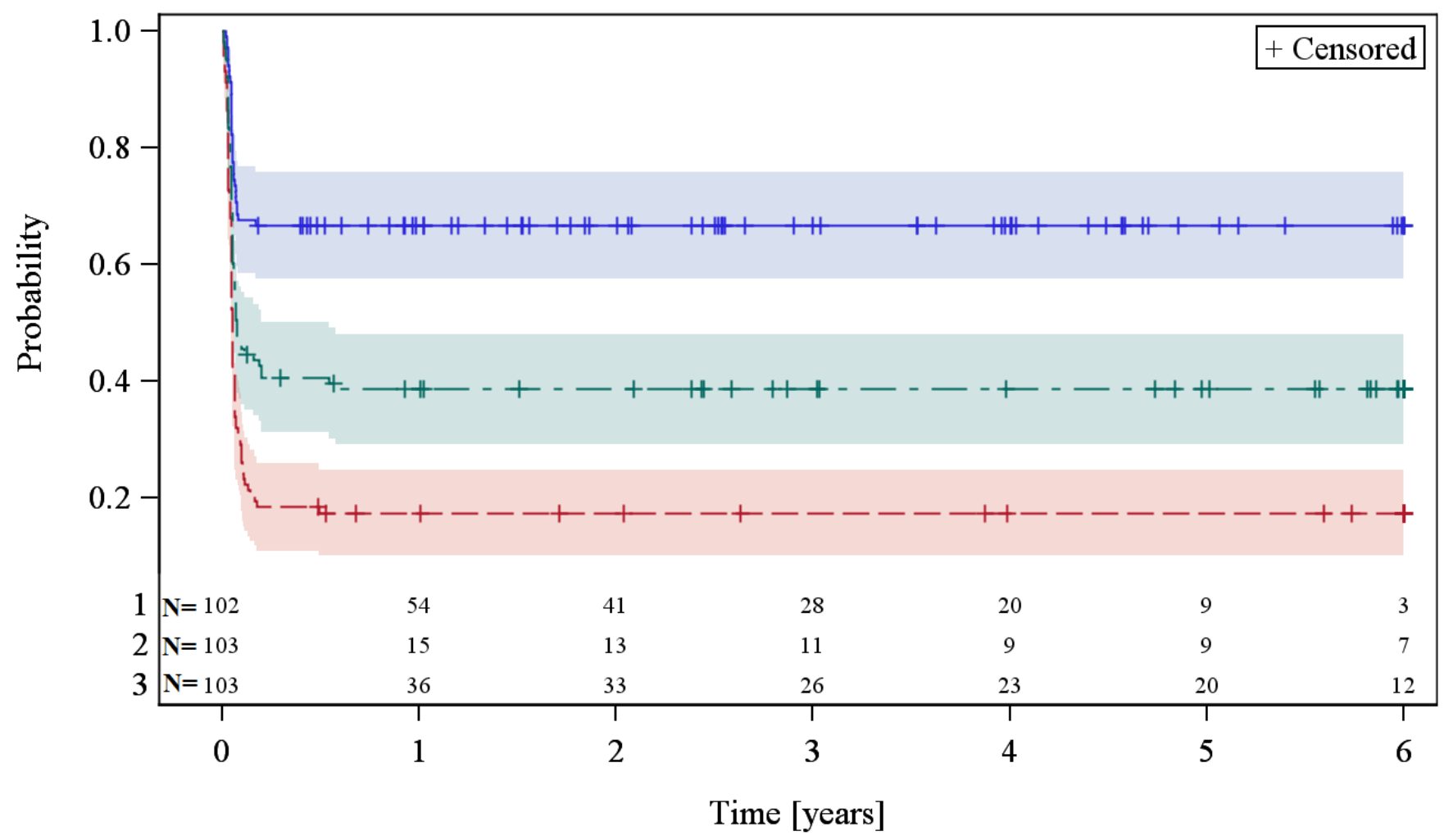

1: Hypertensive on ACEIs - - - 2: Hypertensive not on ACEIs $--\quad 3$ : Non-hypertensive not on ACEIs

Figure (2): Kaplan Meier curves show time to event between hypertensive patients on ACEIs, nonhypertensive patients not on ACEIs and hypertensive not on ACEIs groups over a median 6 years of follow-up. 


\section{Time to resolution of proctitis}

with 95\% Confidence Limits

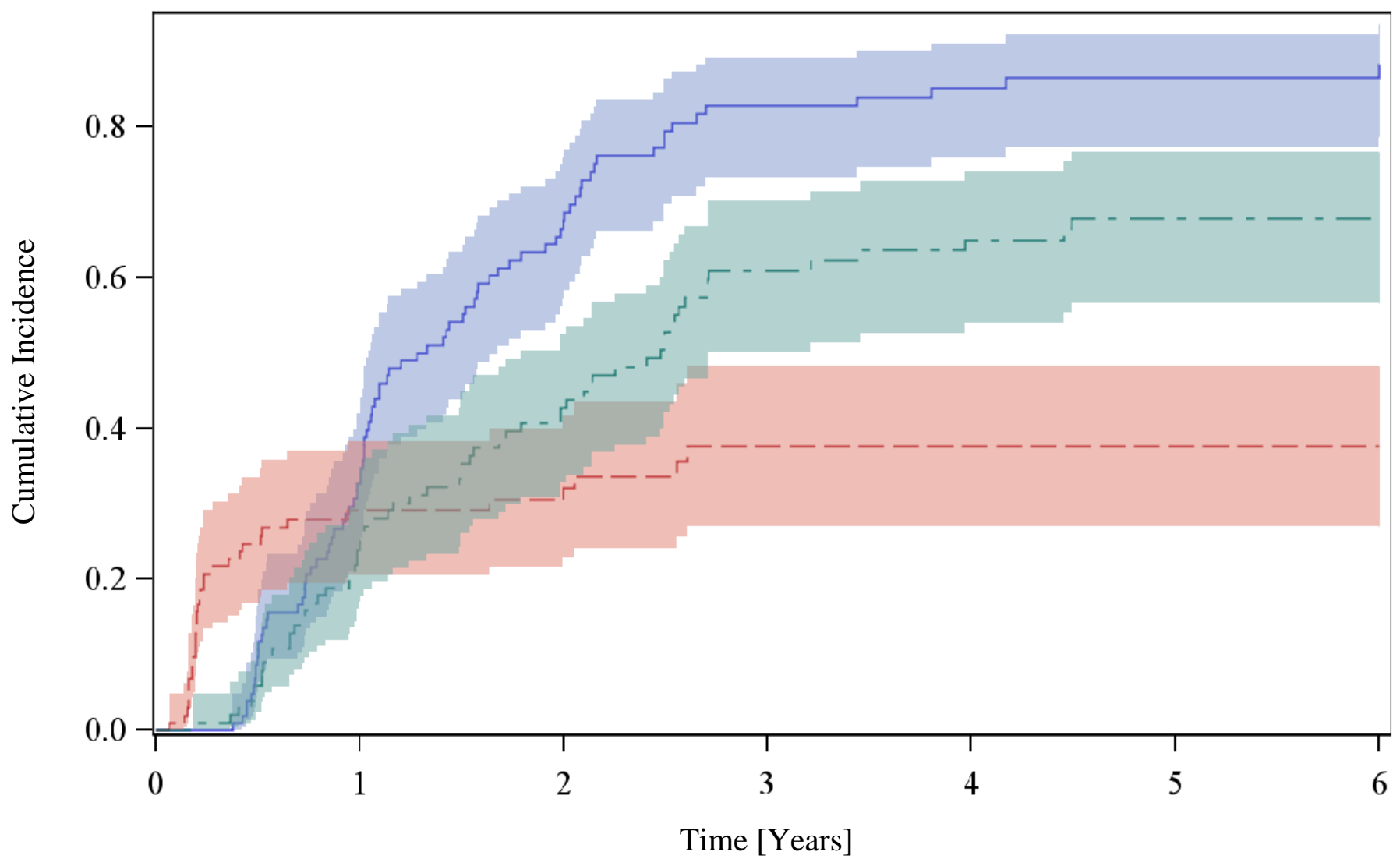

Hypertensive not on ACEIs
$\mathrm{N}=85$
50
17

2

1

1

1

Non-hypertensive not on ACEIs

$\mathrm{N}=63$

37

21

5

2

0

0

Hypertensive on ACEIs
$\mathrm{N}=34$
5
3
0
0
0
0

Figure (3): Cumulative incidence curve show time to resolution between hypertensive patients on ACEIs, non-hypertensive patients not on ACEIs and hypertensive not on ACEIs groups over a median 6 years of follow-up. 


\begin{tabular}{|c|c|c|}
\hline Grade & Sign and symptoms & Overall management \\
\hline $\mathbf{0}$ & No symptoms & Does not require medication \\
\hline 1 & $\begin{array}{l}\text { Minimal side effect such as urgency, } \\
\text { occasional pain, superficial ulceration, }< \\
1 \mathrm{~cm}^{2} \text {, mild stricture and occult rectal } \\
\text { bleeding }\end{array}$ & $\begin{array}{l}\text { Treated as outpatient and does not } \\
\text { require lifestyle adjustments. }\end{array}$ \\
\hline 2 & $\begin{array}{l}\text { Intermittent urgency and pain, superficial } \\
\text { ulceration }>1 \mathrm{~cm}^{2} \text {, intermittent rectal } \\
\text { bleeding and moderate stricture }\end{array}$ & $\begin{array}{l}\text { Treated as outpatient and requires } \\
\text { lifestyle adjustments. }\end{array}$ \\
\hline 3 & $\begin{array}{l}\text { Persistent urgency, pain and bleeding, } \\
\text { deep ulceration associated with sever } \\
\text { stricture }\end{array}$ & $\begin{array}{l}\text { Needs hospital admission or minor } \\
\text { surgical intervention associated radical } \\
\text { adjustment of the lifestyle }\end{array}$ \\
\hline 4 & $\begin{array}{l}\text { Sever urgency associated with sever } \\
\text { uncontrollable pain, sever bleeding, } \\
\text { perforation, fistula and complete } \\
\text { obstruction }\end{array}$ & $\begin{array}{l}\text { Needs hospital admission or major } \\
\text { surgical intervention }\end{array}$ \\
\hline 5 & Multi-organ failure, sepsis and death & Fatal side effects \\
\hline
\end{tabular}

Table 1: Grades of proctitis. 
Before propensity score matching After propensity score matching

\begin{tabular}{|c|c|c|c|c|c|c|c|c|}
\hline Covariate & Group1 & Group2 & Group3 & $\mathrm{P}$ & Group1 & Group2 & Group3 & $\mathrm{P}$ \\
\hline Number & 183 & 428 & 206 & & 102 & 103 & 103 & \\
\hline \multicolumn{9}{|l|}{ Age years } \\
\hline Mean & 68.93 & 66.49 & 69.54 & $<0.001$ & 68.64 & 69.61 & 68.49 & $<0.313$ \\
\hline SD & 5.87 & 7.29 & 6.08 & & 5.31 & 5.59 & 6.11 & \\
\hline Range & $52-90$ & $49-90$ & $53-89$ & & $55-79$ & $56-83$ & $52-89$ & \\
\hline \multicolumn{9}{|l|}{$\begin{array}{l}\text { Follow-up } \\
\text { (Y) }\end{array}$} \\
\hline Mean & 2.98 & 3.38 & 3.11 & $<0.067$ & 3.24 & 3.73 & 3.15 & $<0.074$ \\
\hline SD & 1.95 & 2.10 & 2.10 & & 1.90 & 2.10 & 1.82 & \\
\hline G.S & & & & $<0.502$ & & & & $<0.919$ \\
\hline $2-6$ & 28 & 82 & 44 & & 14 & 13 & 14 & \\
\hline $7(3+4)$ & 48 & 116 & 47 & & 30 & 30 & 25 & \\
\hline $7(4+3)-10$ & 106 & 230 & 112 & & 58 & 60 & 64 & \\
\hline Comorbidity & & & & $<0.001$ & & & & $<0.988$ \\
\hline Non & 98 & 331 & 117 & & 55 & 58 & 55 & \\
\hline 1 & 64 & 85 & 68 & & 33 & 33 & 35 & \\
\hline$\geq 2$ & 21 & 12 & 21 & & 14 & 12 & 13 & \\
\hline PSA (BT) & & & & $<0.225$ & & & & $<0.791$ \\
\hline$\leq 10$ & 73 & 155 & 72 & & 42 & 42 & 45 & \\
\hline $10-20$ & 57 & 158 & 63 & & 33 & 27 & 30 & \\
\hline$>20$ & 53 & 115 & 71 & & 27 & 34 & 28 & \\
\hline Stages & & & & $<0.804$ & & & & $<0.796$ \\
\hline T0 & 1 & 3 & 1 & & & & & \\
\hline $\mathrm{T} 1$ & 14 & 42 & 22 & & 7 & 9 & 6 & \\
\hline $\mathrm{T} 2$ & 84 & 171 & 93 & & 45 & 38 & 41 & \\
\hline $\mathrm{T} 3$ & 80 & 200 & 81 & & 50 & 56 & 56 & \\
\hline $\mathrm{T} 4$ & 4 & 12 & 6 & & & & & \\
\hline Grades & & & & & & & & $<0.001$ \\
\hline Grade 0 & - & - & - & & 68 & 40 & 18 & \\
\hline Grade 1 & - & - & - & & 30 & 22 & 50 & \\
\hline Grade 2 & - & - & - & & 3 & 32 & 25 & \\
\hline Grade 3 & - & - & - & & 1 & 7 & 8 & \\
\hline Grade 4 & - & - & - & & 0 & 2 & 2 & \\
\hline Grade 5 & - & - & - & & 0 & 0 & 0 & \\
\hline
\end{tabular}

Table (2): Propensity score matching; group 1: hypertensive on ACEIs; Group 2: Nonhypertensive not on ACEIs; Group 3: hypertensive not on ACEIs; GS: Gleason score; Y: years; BT: before treatment. 


\begin{tabular}{|c|c|c|c|c|c|c|}
\hline & \multicolumn{5}{|c|}{ Grade } & \multirow[b]{2}{*}{ Total } \\
\hline Patients & Grade 0 & Grade 1 & Grade 2 & Grade 3 & Grade 4 & \\
\hline \multicolumn{7}{|l|}{ Group 1} \\
\hline Count & 68 & 30 & 3 & 1 & 0 & 102 \\
\hline$\%$ within patients & $66.7 \%$ & $29.4 \%$ & $2.9 \%$ & $1 \%$ & $0 \%$ & $100 \%$ \\
\hline \%within grade & $54 \%$ & $29.4 \%$ & $5 \%$ & $6.2 \%$ & $0 \%$ & $33.1 \%$ \\
\hline$\%$ of total & $22.1 \%$ & $9.7 \%$ & $1 \%$ & $0.3 \%$ & $0 \%$ & $33.1 \%$ \\
\hline \multicolumn{7}{|l|}{ Group 2} \\
\hline Count & 40 & 22 & 32 & 7 & 2 & 103 \\
\hline \%within patients & $38.8 \%$ & $21.4 \%$ & $31.1 \%$ & $6.8 \%$ & $1.9 \%$ & $100 \%$ \\
\hline \%within grade & $31.7 \%$ & $21.6 \%$ & $53.3 \%$ & $43.8 \%$ & $50 \%$ & $33.4 \%$ \\
\hline$\%$ of total & $13 \%$ & $7.1 \%$ & $10.4 \%$ & $2.3 \%$ & $0.6 \%$ & $33.4 \%$ \\
\hline \multicolumn{7}{|l|}{ Group 3} \\
\hline Count & 18 & 50 & 25 & 8 & 2 & 103 \\
\hline \%within patients & $17.5 \%$ & $48.5 \%$ & $24.3 \%$ & $7.8 \%$ & $1.9 \%$ & $100 \%$ \\
\hline \%within grade & $14.3 \%$ & $49 \%$ & $41.7 \%$ & $50 \%$ & $50 \%$ & $33.4 \%$ \\
\hline$\%$ of total & $5.8 \%$ & $16.2 \%$ & $8.1 \%$ & $2.6 \%$ & $0.6 \%$ & $33.4 \%$ \\
\hline \multicolumn{7}{|l|}{ Total } \\
\hline Count & 126 & 102 & 60 & 16 & 4 & 308 \\
\hline$\%$ within patients & $40.9 \%$ & $33.1 \%$ & $19.5 \%$ & $5.2 \%$ & $1.3 \%$ & $100 \%$ \\
\hline \%within grade & $100 \%$ & $100 \%$ & $100 \%$ & $100 \%$ & $100 \%$ & $100 \%$ \\
\hline$\%$ of total & $40.9 \%$ & $33.1 \%$ & $19.5 \%$ & $5.2 \%$ & $1.3 \%$ & $100 \%$ \\
\hline
\end{tabular}

Table (3): Patients x grades cross-tabulation; Group 1: hypertensive on ACEIs; Group 2: nonhypertensive not on ACEIs; Group 3: hypertensive not on ACEIs. 
